NASA Technical Memorandum 102339

\title{
Evolutionary Growth for Space Station Freedom Electrical Power System
}

Matthew F. Marshall

Rockwell International

Rocketdyne Division

Canoga Park, California

Kerry L. McLallin and Michael J. Zernic

Lewis Research Center

Cleveland, Ohio

Prepared for the

24th Intersociety Energy Conversion Engineering Conference

cosponsored by the IEEE, AIAA, ANS, ASME, SAE, ACS, and AIChE Washington, D.C., August 6-11, 1989 


\title{
EVOLUTIONARY GROWTH FOR SPACE STATION FREEDOM ELECTRICAL POWER SYSTEM
}

\author{
Matthew F. Marshal1 \\ Rockwe11 International/Rocketdyne Division \\ Canoga Park, CA 91303 \\ Kerry L. McLallin and Mike J. Zernic \\ National Aeronautics and Space Administration \\ Lewis Research Center \\ Cleveland, OH 44135
}

\begin{abstract}
Over an operational lifetime of at least $30 \mathrm{yr}$, Space Station Freedom will encounter increased space station user requirements and advancing technologies. The space station electrical power system is designed with the flexibility to accommodate these emerging technologies and expert systems and is being designed with the necessary software hooks and hardware scars to accommodate increased growth demand. The electrical power system is planned to grow from the initial $75 \mathrm{~kW}$ up to $300 \mathrm{~kW}$. The Phase I station will utilize photovoltaic arrays to produce the electrical power; however, for growth to $300-\mathrm{kW}$, solar dynamic power modules will be utilized. Pairs of $25-\mathrm{kW}$ solar dynamic power modules will be added to the station to reach the power growth level. The addition of solar dynamic power in the growth phase places constraints in the initial space station systems such as guidance navigation and control, external thermal, truss structural stiffness, computational capabilities and storage which must be planned-in in order to facilitate the addition of the solar dynamic modules.
\end{abstract}

\section{INTRODUCTION}

The National Aeronautics and Space Administration (NASA) is currently in the hardware/software design, development, test, and evaluation phase of the Space Station Freedom (SSF) Program. Because the SSF is intended to be an orbital facility with a minimal useful life of $30 \mathrm{yr}$, its design must accommodate the addition of future hardware and software and changeout or upgrading of various components and elements, as well as inherent ease in maintenance. Establishing hooks and scars in the SSF initial design will not pin down a specific growth configuration but will permit viable growth options to be incorporated. Hooks refers to the ability of software to accept upgrades in capacity and capability, while scars refers to the hardware equivalent.
Figure 1 shows the Phase I SSF. It contains one habitation module and three laboratory modules (United States, European, Japanese), has a crew of six to eight astronauts, delivers $75 \mathrm{~kW}$ of electric power to users, and has two to four active attached payload accommodations on the truss. The final growth station will have up to $300 \mathrm{~kW}$ of power available; a crew of 24 ; up to three habitation and six laboratory modules; three pressurized mini laboratories; provisions for 18 attached payload accommodations; facilities to maintain, service, and deploy orbital maneuvering vehicles, orbital transfer vehicles, and free flying platforms; and will provide support to the construction of large space structures. [1]

\section{GROWTH SCENARIOS}

The path from the first phase of SSF to its growth configuration is a path of increasing user resource demands. There is a diverse spectrum of groups that would like to use SSF. First among these are the experiments users who are divided into several utilization scenarios: astrophysics and terrestrial observations, biological observations, and materials processing experiments. Astrophysics and terrestrial observation scenarios require an increase in the SSF truss work with provisions for attaching additional external payloads. Astrophysics growth scenarios require mounting on the top of SSF to facilitate

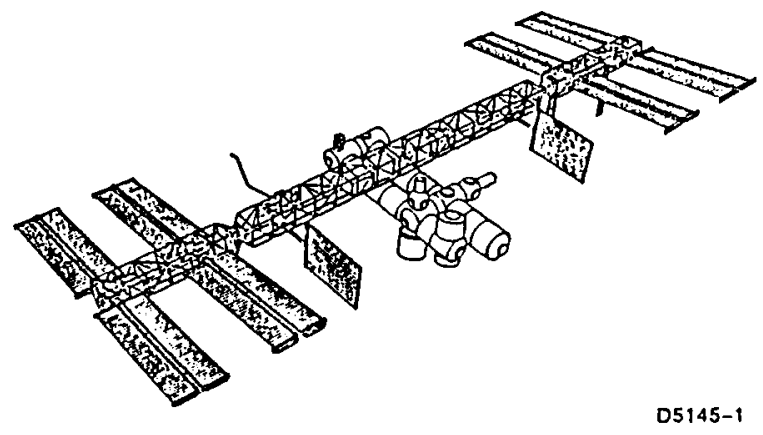

Figure 1. Space Station Freedom Phase I Configuration 
astrophysics observations, while mounting to the bottom of SSF offers the widest field of view for terrestrial-looking experiments. Biological and materials processing growth scenarios require an increase in the pressurized laboratory volume, which can be accommodated through the addition of laboratory modules.

A second group of users desire to use SSF as a transportation node for spacecraft such as the Orbital Maneuvering Vehicle or Orbital Transfer Vehicle, which will be used in going from low Earth orbit to higher orbits in order to deploy and retrieve payloads. A third user group would like to use SSF to repair and refurbish satellites and payloads recovered with the vehicles from the transportation node users. The second and third utilization areas require additional truss structure as well as hanger space in order to dock the vehicles and satellites that will be serviced and repaired.

A fourth user could be concerned with learning more about how persons function and live under long exposure to a weightless and limited habitable volume situation in preparation for future long duration missions to the moon or Mars.

The growth of SSF cannot occur without more available crew members. Regardless of how many missions or user experiments and payloads are on-orbit, the lack of crew resources will severely impact the scheduling and operations. One of the first things to be added is the quantity of crew available to operate experiments and payloads and to carry out science and technology missions, which implies the addition of more habitation modules. More laboratory modules are also needed to expand upon the facility's microgravity environment in order to conduct space research and development. In ad- dition to increasing the pressurized volume and crew availability, more external attached payloads will be manifested at various new locations on the SSF truss.

Figure 2 shows an example of what a $275-\mathrm{kW}$ growth station may look like [2]. Other growth configurations are possible based on using SSF as a transportation node for staging lunar, Mars, or other interplanetary missions. Therefore, growh of the Electric Power System (EPS) is inevitable and the EPS design and architecture must include an evolving capability so as to not preclude any future utilization and capability of SSF:

\section{GROWTH POWER DEMANDS}

Figure 3 shows growth power level requirements as a function of launch capacity and the types of uses of the station [2]. In order to allow aggressive research in life sciences or microgravity science and commercial production of materials, pharmaceutical products, and other experiment applications, SSF should accommodate growth to at least a $275-\mathrm{kW}$ power capability. The capability to grow to this level is determined by the type of experi-

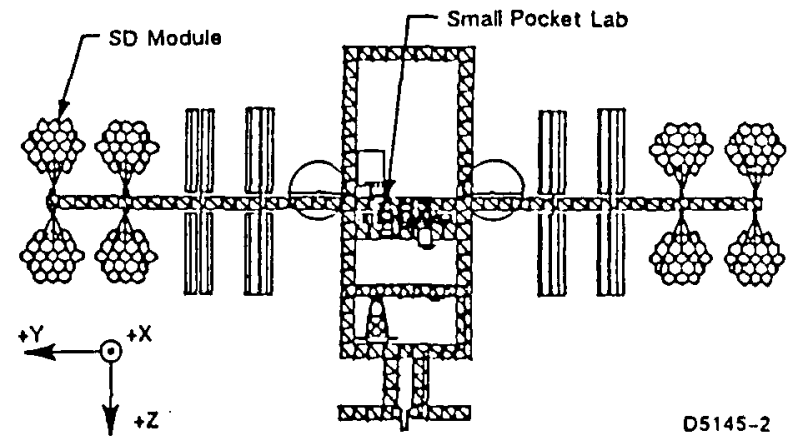

Figure 2. A 275-kW Growth Station

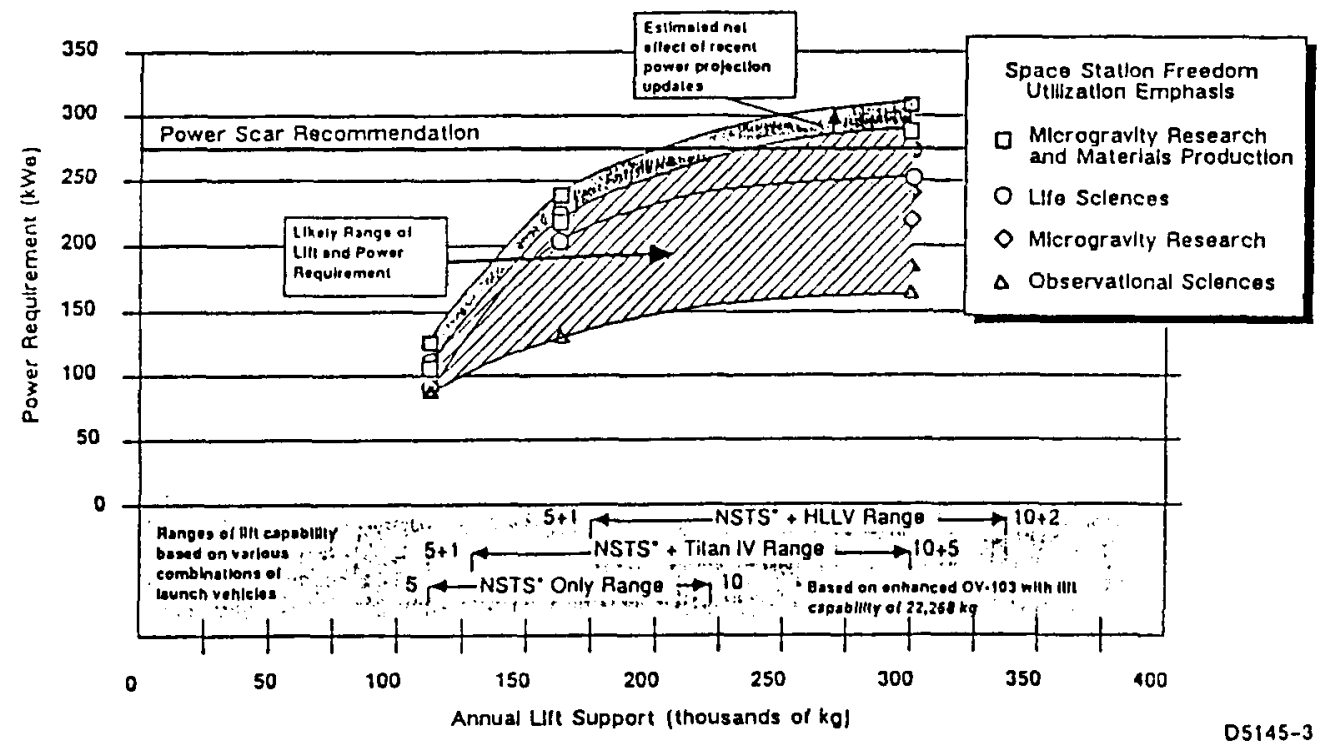

Figure 3. Space Station Growth Power Requirements 
mentation being carried out on SSF and the level of launch support provided.

The launch support dictates the rate and viability of assembly, resupply, user payload quantity and interchangeability, and the addition or upgrading of SSF elements and systems. The lowest growth power level forecast of $150 \mathrm{~kW}$ occurs when observational science experiments represent the majority of the SSF utilization. This level is sufficient for an extensive observational science effort but is an unlikely scenario for some of the other planned uses. The highest power level anticipated is approximately $300 \mathrm{~kW}$ and is primarily driven by commercial research and development and production methods of materials and pharmaceuticals. However, this scenario requires extensive launch and return transportation support (probably a mixture of space shuttle and expendable launch vehicles [ELVs]) for resupply and returning processed materials back to Earth. This power level also implies a busy activity schedule and the associated crew and resources to complete the expected objectives [2].

\section{ELECTRIC POWER SYSTEM GROWTH}

Evolution and growth of the EPS addresses both the power generation (method and quantity) as well as the power distribution based upon the power demand. The power demand on the EPS comprises two parts: (1) power needed to run the inherent SSF facility and systems equipment (life support, lighting, propulsion, data processing, etc.) and (2) power for the equipment needed to operate experiments or payloads conducting research in various science and technology disciplines.

As currently planned, SSF will take 21 shuttle flights and 3 yr to complete the assembly of the initial (Phase I) configuration. At the completion of Phase I, the EPS will be capable of delivering $75 \mathrm{~kW}$ of usable power. This power will be drawn upon to satisfy SSF housekeeping needs and operate equipment to accomplish scientific and technology objectives. The initial power generation system will consist of four $18.75-\mathrm{kW}$ photovoltaic (PV) power modules utilizing solar cells to transform incident solar energy into electrical power. Each PV module consists of two solar arrays, each approximately $100 \mathrm{ft}$ long by $33 \mathrm{ft}$ wide. The PV arrays were chosen for the Phase I station because of their lightweight deployable characteristics and their solar off-pointing power generating capability, which is especially important during the assembly buildup of SSF. However, the addition of PV modules for growth would impact the station guidance navigation and control (GN\&C) system and would require more frequent altitude reboost because of the increased drag area of the large solar array surface area.

As more power generation capability is added, performance and efficiency become more important. Solar dynamic (SD) power offers performance, efficiency, and cost savings advantages over PV power that make it an excellent choice for the growth power system.

\section{SOLAR DYNAMIC POWER GENERATION FOR GROWTH}

The SD power generation system has been selected to provide the additional power required for SSF growth phases. This selection is based on the significant efficiency gains (approximately twice the power output at half the surface area of PV) and life cycle cost (LCC) savings projected for SD versus growth with a PV power generation system. Life cycle cost analyses have been performed to determine critical cost elements and to define the LCC for various power generation options. The LCC elements considered for these analyses consisted of the nonrecurring costs due to design, development, test, and evaluation as well as the recurring costs associated with production, growth, and operations. Each category of recurring cost included consideration of the hardivare, launch and transportation, and deployment and installation costs. The LCC were evaluated for up to $30 \mathrm{yr}$ of operation and for up to $300 \mathrm{~kW}$ of power generation capacity. Typical results from these analyses are presented in Figure 4. Life cycle costs for $30 \mathrm{yr}$ (in fixed 1987 dollars) are presented versus the final SSF power level for three cases. These cases illustrate the basic cost trends and the sensitivity to the split of $P V$ and $S D$ power. The data indicate that over the 30-yr life of SSF growing with SD will reduce $L C C$ by $\$ 3.3$ billion, compared to an all PV station, and that additional benefits could be realized by minimizing the level of $P V$ power for the station.

The LCC advantage of SD over PV is due primarily to the lower flight hardware costs required for growth, operations, and maintenance of the power generation system. Another significant advantage of $S D$ is related to its high sun-to-user conversion efficiency. This translates into lower total surface area required to convert sunlight to electricity and hence lower on-orbit drag. The station can fly at lower altitudes while maintaining safe

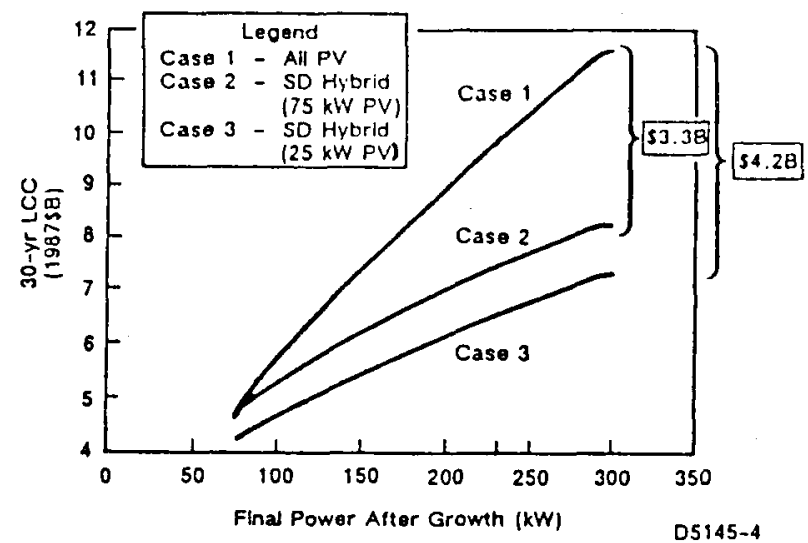

Figure 4. EPS Life Cycle Cost 
orbital lifetimes, which will allow larger space transportation system (STS) payloads for station resupply.

The SD power generation is configured as individual modules, each producing a minimum of $25-\mathrm{kW}$ net elec. tric power. The SD configuration is shown in Figure 5. The module consists of a solar concentrator assembly with vernier pointing gimbals; a receiver/power conversion unit subsystem with thermal energy storage; a heat rejection assembly with a thermal control cold plate for the electrical equipment; WP-04-furnished beta gimbal, frequency changer, and controllers; and WP-02-furnished truss bays and cable trays. The SD module uses a recuperated Brayton cycle to convert solar energy into electricity via a turbine-driven alternator. At the minimum power design point, the SD module has a sun-touser efficiency of approximately $20 \%$. A constant power level is delivered to the user continuously around the orbit, since the receiver incorporates thermal energy storage to support power generation during eclipse [3].

Some of the key SD module design requirements follow:

(1) Provide a minimum of $25-\mathrm{kWe}$ net power throughout any orbit at any time of the year within a prescribed orbit altitude envelope.

(2) Provide $28.75 \mathrm{kWe}$ (peaking power) for up to 7.5 min during the sun and shade portions of the orbit (no more than $15 \mathrm{~min}$ total per orbit).

(3) Provide automatic startup, shutdown and continuous operation capability.

(4) Employ common hardware, software, and standard interfaces to the maximum beneficial extent.

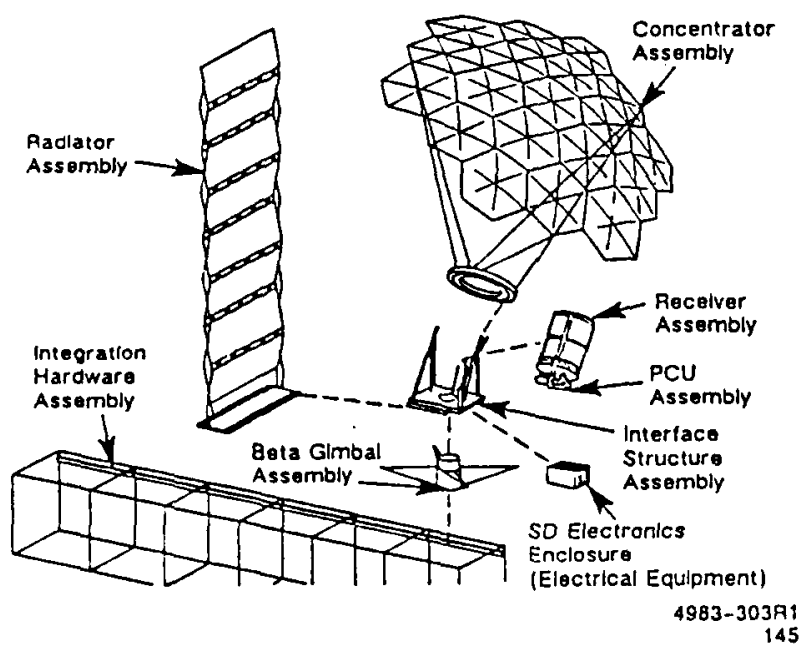

Figure 5. Solar Dynamic Module Confjguration
(5) Establish the moment of inertial such that dynamic instabilities do not occur.

(6) Meet load demand changes, including peaking, turndown, and load shedding.

(7) Remain operational indefinitely through orbital replacement unit (ORU) replacement.

(8) Package two SD modules, along with the necessary truss, into one space shuttle launch.

Although SD power will not be utilized until Phase II, significant work must be done in Phase I to pave the way for the addition of SD modules for growth. The SD power system design effort in Phase I includes a task to define the software hooks and hardware scars required of SSF systems and elements to adequately support the addition of SD modules for growth phases of the program. The areas of consideration are briefly described in Table 1 [4]. As SD module requirements are defined in these areas, they are coordinated with the interfacing systems and elements and documented. If necessary, the program requirements documents would be updated to reflect the identified impacts.

\section{DISTRIBUTED ELECTRIC POWER SYSTEM GROWTH}

The power management and distribution system (PMAD) is initially sized to be able to distribute more power than is available during Phase I. Major EPS components that are expected to last the lifetime of SSF are initially sized to handle the total maximum power capability of at least $300 \mathrm{~kW}$. The two SSF alpha gimbals are each sized to allow $175 \mathrm{~kW}$ (350 kW total) of power to flow from the two outboard solar power modules to the inboard truss users. The cabling to the two inboard truss main bus switching units is also sized to $175 \mathrm{~kW}$ each. This initial sizing to the growth capability avoids the major complexity and power downtime of removing and replacing hardware or adding in greater capacity during growth. Space is provided in the truss cable trays to allow the addition of cabling from the main bus switching units to growth power distribution and control units associated with the addition of pressurized modules or attached payload accommodations. Trades establish what level of growth is allowed for in the initial design.

\section{TECHNOLOGY TRANSPARENCY}

The EPS has a built-in capability for addition or substitution of new technology with minimum impact to operations and interfaces. This feature is called technology transparency. The selection criteria for the appropriate degree of technology transparency in the design is a function of:

(1) Technology Evolution Maturity. Structures and mechanisms have a high degree of maturity and 
Table 1. Solar Dynamic Hooks and Scars

\begin{tabular}{|c|c|}
\hline Issues & Design Consideration \\
\hline GN\&C & SSF must be controllable with addition of SD modules. \\
\hline Power growrh and utilization & $\begin{array}{l}\text { The power distribution system must accommodate additional power } \\
\text { input by } S D \text { and accommodate SD power needs for startup. shut- } \\
\text { down, and housekeeping. }\end{array}$ \\
\hline Structure & $\begin{array}{l}\text { SSF truss and alpha and beta gimbals must accommodate mass, } \\
C G \text {, and MOI of SD and be sufficiently stiff to allow accurate } \\
\text { point and tracking. }\end{array}$ \\
\hline Thermal environments & $\begin{array}{l}\text { SSF must accommodate modification to thermal environment re- } \\
\text { suling from addition of SD modules. }\end{array}$ \\
\hline Off-axis phenomena & $\begin{array}{l}\text { SSF must accommodate off-axis phenomena such as optical, radio } \\
\text { frequency, and infrared concentrations and signatures. }\end{array}$ \\
\hline DMS & $\begin{array}{l}\text { SSF must accommodate additional data input resulting from power } \\
\text { growth. }\end{array}$ \\
\hline Communication and tracking & $\begin{array}{l}\text { SSF must accommodate additional data input resulting from power } \\
\text { growth. }\end{array}$ \\
\hline MSC & $\begin{array}{l}\text { The MSC must accommodate the masses and ranges of motion } \\
\text { required to assembly the } S D \text { power module. }\end{array}$ \\
\hline
\end{tabular}

D658-0014

would therefore require less technology transparency than the relatively low maturity of automation and robotics or expert systems.

(2) Prediclability of Upgrade and Technology Life. As an example, computers and software evolve rapidly and thus would warrant a high degree of technology transparency.

(3) Development Time and Cost. Hardware evolves more slowly than software.

(4) Applicability of Technology to Other Potential User Markets. The rate of development is in large part dependent on the needs.

These selection criteria are applied to three categories of advancing technology (near-, mid-, and farterm) to determine the level of technology transparency in the baseline design.

Near-term technologies are not currently mature but are incorporated in the completed Phase I configuration because their projected development conforms with the SSF schedule. Near-term technologies include controllers enhanced by expert systems for fault diagnostics, trend analysis, solar array orientation, and load distribution and switching [5].

Mid-term technologies are currently under development but will not reach maturity until after the SSF Program Critical Design Review around 1992. These technologies can provide significant potential cost or operations beriefits and productivity enhancements to the SSF
EPS and are accommodated in the Phase I configuration through specific technology features. Exampies of midterm technologies are autonomous intelligent controllers for fault detection and isolation, power management, and maintenance scheduling [5].

Far-term technology involves major technological innovations and unique new program needs that have yet to be identified.

The WP-04 approach to technology transparency accommodates near-term technology in the Phase I design; mid-and far-term technologies are accommodated through software and hardware functional modularity. layering, isolation of functions from interfaces, physical and functional standardization of utilities, and interface standardization. This allows the EPS to take advantage of approaching technologies to improve the efficiencies and capabilities of the design.

\section{ACKNOWLEDGMENTS}

The authors thank Tom Shanahan for the approach to technology transparency, Kelly Newton for examples of advanced technology, and Marty Garey for making this paper possible.

\section{REFERENCES}

[1] Space Station Program Office, 1988, "Space Station Program Definition and Requirements Section 3: Space Station Systems Requirements," SSP 30000 Section 3, Revision G., Space Station Program Office, Reston, Virginia. 
[2] McDonnell Douglas Space Systems Company, Engineering Services under contract NAS1-18227 to NASALungley Research Center.

[3] Rocketdyne, 1988, DR: SE-02, Power Systems Description Document, RI/RD 88-633, Rockwell International, Rocketdyne Division, Canoga Park, California.

[4] Rocketdyne, 1988, DR: SE-03, Supporting Engi- neering Analysis and Data - System Assessment Report, RVRD 88-637, Rockwell International, Rocketdyne Division, Canoga Park, California.

[5] NASA, 1988, "Advancing Automation and Rubulics Technology for the Space Station and for the U.S. Economy - Progress Report 6." NASA Technical Memorandum 100989, NASA-Johnson Space Center, Houston, Texas. 


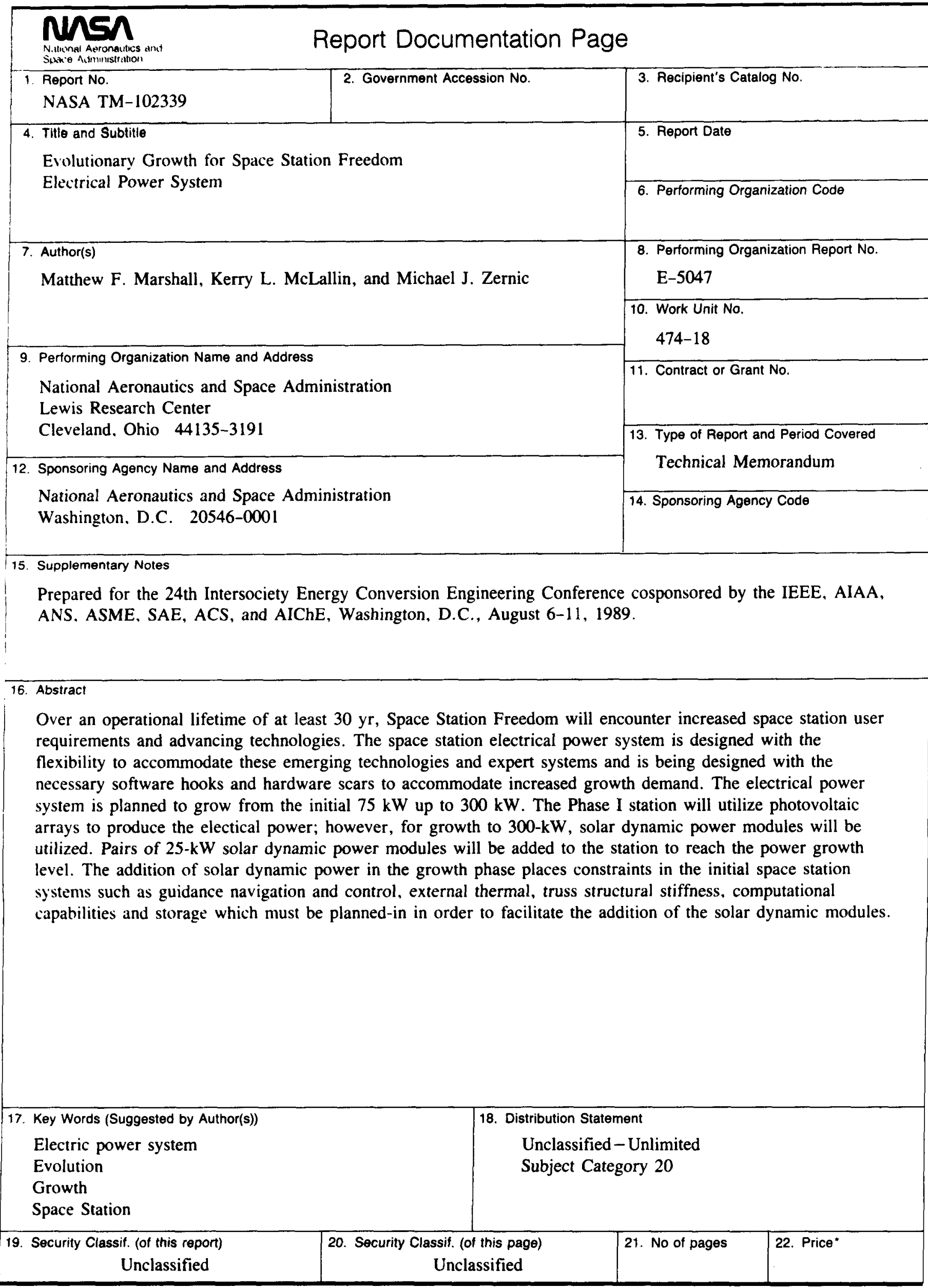

